\title{
EMMA HERDMAN, Louis Des Masures, Claude Goudimel et Jean de Tournes
}

\section{Filippo Fonio}

\section{(2) OpenEdition \\ Journals}

\section{Edizione digitale}

URL: http://journals.openedition.org/studifrancesi/33001

DOI: 10.4000/studifrancesi.33001

ISSN: 2427-5856

\section{Editore}

Rosenberg \& Sellier

\section{Edizione cartacea}

Data di pubblicazione: 1 décembre 2005

Paginazione: 626

ISSN: 0039-2944

\section{Notizia bibliografica digitale}

Filippo Fonio, «emma herdman, Louis Des Masures, Claude Goudimel et Jean de Tournes», Studi Francesi [Online], 147 (XLX | III) | 2005, online dal 01 novembre 2015, consultato il 20 avril 2021. URL: http:// journals.openedition.org/studifrancesi/33001; DOI: https://doi.org/10.4000/studifrancesi.33001

Questo documento è stato generato automaticamente il 20 avril 2021.

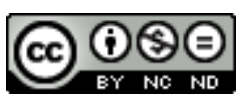

Studi Francesi è distribuita con Licenza Creative Commons Attribuzione - Non commerciale - Non opere derivate 4.0 Internazionale. 


\title{
EMMA HERDMAN, Louis Des Masures, Claude Goudimel et Jean de Tournes
}

\author{
Filippo Fonio
}

\section{NOTIZIA}

EMMA HERDMAN, Louis Des Masures, Claude Goudimel et Jean de Tournes, «Bibliothèque d'Humanisme et Renaissance», LXVI, 3 (2004), pp. 607-616.

1 Lo studio dei Vingtsix Cantiques chantés au Seigneur di Louis Des Masures (Lyon, Jean de Tournes, 1564) si inserisce nella problematica dei rapporti fra musica e poesia nel Rinascimento. I Vingtsix Cantiques, la cui partitura è generalmente attribuita a Claude Goudimel, vengono situati dalla studiosa nell'ambito della politica editoriale 'musicale' di Jean de Tournes, nonché delle controversie religiose del tempo. Opera successiva alla conversione di Des Masures alla Riforma, vi si ritrova l'influsso della traduzione dei Salmi curata da Clément Marot e Théodore de Bèze (al quale i Vingtsix Cantiques sono dedicati), come delle riprese dalle Cuvres poëtiques di Des Masures (1557), rilette in chiave più manifestamente pedagogica e in accordo alla spiritualità riformata. 